\title{
ALGUNS APONTAMENTOS SOBRE A ORIGEM DAS PSICOTERAPIAS FENOMENOLÓGICO-EXISTENCIAIS
}

\author{
A Few Notes about the Origin of the Phenomenological-existential Psychotherapies
}

Algunos Apuntes sobre el Origen de las Psicoterapias Fenomenológico-existenciales

BEATRIZ FURTADO LIMA

\begin{abstract}
Resumo: A Psicologia foi marcada por fundamentos filosóficos na Fenomenologia, Existencialismo e Humanismo. Tais perspectivas modificaram a forma de se conceber o homem e de se fazer ciência, contribuindo também para o surgimento das psicoterapias de cunho fenomenológico-existenciais. $\mathrm{O}$ artigo faz um breve percurso histórico pelas principais linhas de pensamento que embasam as psicoterapias de tal abordagem, mencionando os filósofos e psicoterapeutas mais importantes. O estudo inicia discutindo as primeiras mudanças de perspectivas, quando, superando a visão mecanicista, o homem começa a ser considerado parte de um sistema funcional de interconexões com o mundo, surgindo, posteriormente, a Psicologia do Ato de Brentano e a Fenomenologia de Husserl. Em seguida, apresenta o Existencialismo, quando o homem passa a ser reconhecido como um ser livre e capaz de construir sua própria história; e o movimento Humanista, quando foram despertados muitos valores humanos como a potencialidade e a tendência ao crescimento. Por fim, discutem-se as principais noções e conceitos chaves que, oriundos das correntes de pensamento citadas anteriormente, caracterizam as psicoterapias de cunho fenomenológico-existenciais como sendo uma abordagem que reconhece a liberdade humana e respeita o cliente como um ser capaz de encontrar seu próprio caminho uma vez que se encontre em um ambiente favorecedor.

Palavras-chave: Fenomenologia; Existencialismo; Humanismo; Psicoterapias.
\end{abstract}

\begin{abstract}
Psychology has been influenced by philosophical fundaments from the Phenomenological, Existential, and Humanist movements. Such prospect changed the way of conceiving man and making science, contributing, as well, to the emergence of the phenomenological-existential psychotherapies. This paper presents a brief historical journey through the main lines of thought that fundament the psychotherapies of such approach, mentioning the most important philosophers and psychotherapists. The study begins discussing the first perspective changes, when, overcoming the mechanistic point of view; the man begins to be considered part of a functional system interconnected with the world. It is shown that, afterwards, arise the Act Psychology of Brentano and Husserl's Phenomenology. Subsequently, presents the Existentialism, when man is recognized as a free being and able to build its own history; and the Humanist movement, when many human values are revealed such as the human potential and tendency to growth. Finally, it is discussed the main ideas and concepts, from the thoughts mentioned above, that characterize the phenomenological-existential psychotherapies as an approach that recognizes human freedom and respects the client as someone able to find their own way once immersed in a favorable environment.
\end{abstract}

Keywords: Phenomenology; Existentialism; Humanism; Psychotherapies.

Resumen: La Psicología fue influida por fundamentos filosóficos de la Fenomenología, del Existencialismo y del Humanismo. Tales perspectivas modificaron la forma de concebir al hombre y de hacer ciencia, contribuyendo también al nacimiento de las psicoterapias de base fenomenológico-existenciales. El artículo hace un corto recorrido histórico por las principales líneas de pensamiento que fundamentan dichas psicoterapias, mencionando a los filósofos y a los psicoterapeutas más importantes. El estudio se inicia discutiendo los primeros cambios de perspectivas, cuando, superando la visión mecanicista, el hombre empieza a ser considerado parte de un sistema funcional de interconexiones con el mundo, surgiendo, posteriormente, la Psicología del Acto de Brentano y la Fenomenología de Husserl. Luego, presenta al Existencialismo, cuando el hombre pasa a ser reconocido como un ser libre y capaz de construir su propia historia; y al movimiento Humanista, cuando emergen muchos valores humanos como la potencialidad y la tendencia al crecimiento. Finalmente, son discutidas las principales nociones y conceptos claves que, procedentes de las corrientes de pensamiento citadas anteriormente, caracterizan las psicoterapias fenomenológicoexistenciales como un abordaje que reconoce la libertad humana y respeta al cliente como un ser capaz de encontrar su propio camino una vez que se encuentre en un ambiente favorable.

Palabras-clave: Fenomenología; Existencialismo; Humanismo; Psicoterapias.

\section{Introdução}

A Psicologia desenvolveu-se, no decorrer de sua história, fundamentando-se em correntes de pensamento e teorias filosóficas. Durante esse percurso, o qual se ini- cia ainda nas primeiras matrizes mecanicistas, vão surgindo diferentes maneiras de se conceber o homem e de praticar tal ciência. Com o avanço do pensamento científico, evoluem-se as visões de mundo e a Psicologia vai sendo marcada pelas contribuições de importantes pen- 
sadores fenomenológicos e existenciais que cruzaram seu caminho.

A Fenomenologia e o Existencialismo, bem como o movimento Humanista, introduziram um novo modo de se conhecer e trabalhar com o ser humano. O contexto acadêmico atual revela o olhar fenomenológico da Psicologia ao se fazer ciência. É possível perceber também fortes influências de tais perspectivas na postura terapêutica e na relação terapeuta-cliente. Não se concebe ser psicoterapeuta fenomenológico-existencial sem uma compreensão dos fundamentos que embasam tal prática.

Ao longo deste artigo, são discorridos, brevemente, alguns apontamentos sobre a inserção da Fenomenologia, do Existencialismo e do Humanismo na Psicologia, o que resultou no início do movimento Fenomenológicoexistencial e influenciou a postura e o olhar de muitos terapeutas. Serão abordados os principais fundamentos e conceitos chaves que caracterizam as Psicoterapias Fenomenológico-Existenciais.

\section{A Fenomenologia de Husserl}

A Fenomenologia de Husserl constitui-se como uma das maiores contribuições filosóficas para a Psicologia, mais especificamente para as psicoterapias de cunho Fenomenológico-existencial. Ela "propunha um paralelismo entre a psicologia e a fenomenologia, pois toda pesquisa psicológica empírica afirma uma verdade fenomenológica ou eidética, quer dizer, essencial” (Raffaelli, 2004, p. 212). Husserl defendia que o estudo experimental revelaria a essência de maneira velada, cabendo à psicologia desvendá-la e compreendê-la, o que só seria possível havendo uma superação dos preconceitos naturalistas que embasam o experimentalismo (Raffaelli, 2004).

O século XVII, anterior a Husserl, estava marcado pelas influências racionalistas de Descartes, sendo uma época caracterizada pelo Mecanicismo, na qual o mundo e o homem eram vistos como máquinas constituídas de peças com funções específicas e independentes que contribuíam para o ‘todo' a partir do bom desempenho de suas funções. "Pode-se observar claramente uma redefinição das relações sujeito/objeto, seja no plano da ação, seja no do conhecimento. A razão contemplativa (...) cede lugar, progressivamente, à razão e à ação instrumental” (Figueiredo, 1991, p. 13).

Nessa época, tentava-se explicar a natureza, desmembrando-a em partes e, a partir do entendimento de cada parte, garantia-se a explicação do 'todo'. Não se percebia o mundo como um sistema de interconexões e nem se reconhecia a intersubjetividade das ações humanas. Acreditava-se que era possível compreender o homem e o mundo de forma simples e objetiva, estudando atos concretos e isolados, a partir do que era possível observar. Esta atitude fez da ciência a criadora do método científico, dedicada absolutamente ao objetivismo. "A instrumentalidade do conhecimento converte-se numa das determinações internas da ciência, cujos procedimentos e técnicas definem-se nos termos de controle, cálculo e teste" (Figueiredo, 1991, p. 14).

Assim sendo, tem-se a seguinte situação: o conhecedor ('de um lado') que dispõe de um método (o qual elimina do procedimento a sua sensibilidade) para atingir o conhecido ('do outro lado'). Em síntese, esse é o estilo científico-naturalista de produzir conhecimento. É a herança do dualismo cartesiano que, inflando o sujeito com a racionalidade, fez-lhe limitado em sua existencialidade. Pois, seria como se o conhecimento fosse um empreendimento distinto do homem, como se fosse um ponto isolado, que o pesquisador atingiria após despojar-se de sua humanidade viesada, de sua sensibilidade (Roehe, 2006, p. 154).

Tal idéia influenciou muitos estudos e áreas do conhecimento humano, inclusive a Psicologia, a qual, para ser reconhecida como ciência, submeteu-se a essa maneira de pensar. $\mathrm{O}$ atomismo e o pensamento mecanicista foram fortemente marcantes nos estudos humanos na primeira metade do século XIX (Figueiredo, 1991). A evidência empírica era "a base segura para se fundar e validar o conhecimento objetivo" (Figueiredo, 1991, p. 16).

No entanto, com o desenvolvimento da ciência e progressos na forma de perceber o mundo, novas matrizes de pensamento vão surgindo. $\mathrm{O}$ mundo passa a ser visto não apenas pela óptica atomicista e mecanicista, mas também por um prisma funcionalista, organicista, recebendo, inclusive, influência da teoria da evolução de Darwin (Figueiredo, 1991). Darwin contribuiu com suas proposições sobre o evolucionismo, quebrando diversas crenças rígidas que permeavam a ciência e a visão dos seres vivos naquele tempo.

A matriz funcionalista veio trazer uma visão sistêmica de se apreender o mundo, contemplando a inter-relação entre as diversas disciplinas de estudo e as diversas atividades humanas. O homem passa a ser reconhecido como um sistema funcional de interconexões e possibilidades, sendo considerado um fenômeno individual e singular. Tal perspectiva trouxe importantes avanços na compreensão da subjetividade humana.

Assim, novos conceitos vão sendo elaborados e muitos questionamentos começam a surgir. O pensamento positivista vai sendo questionado pela impossibilidade de haver um sujeito inteiramente livre de sua subjetividade. A pura subjetividade passa então a ser considerada uma ilusão.

A percepção do objeto supõe a percepção da sua identidade ao longo de uma sucessão temporal de imagens. Toda percepção implica memória e antecipação; o significado do objeto depende do que recordamos dele (e de objetos semelhantes) e do que esperamos ver dele sob diferentes ângulos (Figueiredo, 2002, p. 176). 
Franz Brentano, opondo-se principalmente aos naturalistas, os quais consideravam o objeto natural, real e exterior, independente às pessoas, lança suas idéias sobre o estudo do ato e, dessa forma, influencia uma nova fase da ciência. Brentano defende que a realidade está na consciência de cada um, na maneira como cada um vive o mundo, como se vê, sente, toca, ouve e percebe. "O fundamental da psicologia brentaniana é que a experiência se baseia na percepção interior" (Holanda, 1998, p. 3). Surge, então, a psicologia do ato, a qual vai distinguir os atos físicos dos atos psíquicos e argumentar que o foco deveria ser no ato psíquico. Ela vai levar em consideração não mais o objeto em questão, mas sim o ato, isto é, não importa a coisa vista, mas o ato de se ver; não importa aquilo que se sente, mas o ato de sentir.

É interessante ressaltar-se que consciência e objeto não são em distinção e efeito duas entidades separadas na natureza, e que o fenomenólogo trataria na seqüência de relacionar. Consciência e objeto se definem respectivamente a partir dessa correlação que lhes é, de certo modo e maneira, cooriginal (Angerami-Camon, 1993, p. 61).

Dessa forma, consciência e objeto são unificados - a mente está sempre em relação, nega-se a pura objetividade e a pura subjetividade. Dá-se início ao estudo da intencionalidade - do ato de dar sentido. Sabendo-se, contudo, que "nunca se chega ao sentido último porque nunca se esclarece totalmente o conjunto de significados e valores dentro do qual a experiência se constitui" (Figueiredo, 2002, p. 177).

No final do século XIX, na Alemanha contemporânea, Edmund Husserl (1883-1969), aluno de Brentano, aprofunda as idéias do seu professor sobre a psicologia do ato e funda o movimento conhecido como Fenomenologia (Giles, 1975). Parece que o termo fenomenologia já havia sido usado no século XVIII por Jean Lambert (Zilles, 1996) e, mais tarde, por Kant e Hegel (Enciclopédia Mirador Internacional, 1982, vol. 9). Porém, foi com Husserl que a Fenomenologia surgiu verdadeiramente como um movimento de pensamento. Para Dartigues (1992), a Fenomenologia nasceu propondo uma terceira via entre a filosofia especulativa da metafísica e a ciência positivista.

Para Husserl, a Fenomenologia seria a descrição dos fenômenos como eles são na intencionalidade da consciência, rejeitando, assim, o elementarismo, o naturalismo. Ou seja, seria a busca pelo fenômeno que se constitui na interação do objeto com a consciência: subjetividade versus objetividade. O objeto só passa a se constituir como tal quando reconhecido e representado na consciência. Sem essa correlação não poderia haver objeto nem tão pouco consciência (Roehe, 2006).

Husserl, assim como Brentano, considera a intencionalidade do ato. No entanto, diferentemente do seu tutor, Husserl se apropria do termo escolástico 'intencionalidade' dando-lhe um outro sentido. Para ele, a intenciona- lidade permitiria investigar o retorno às coisas mesmas, isto é, ao fenômeno. "O fenômeno é para Husserl simplesmente aquilo que se oferece ao olhar intelectual, à observação pura, e a fenomenologia se apresenta como um estudo puramente descritivo dos fatos vivenciais do pensamento e do conhecimento oriundo dessa observação.” (Giles, 1975, p. 132).

Husserl (1900) cria então um método para ter acesso ao fenômeno: a 'redução fenomenológica', a qual consiste em suspender todos os preconceitos, valores, teorias científicas e crenças pré-existentes. "É necessária, pois, a realização consciente da redução fenomenológica para obter aquele eu e a vida da consciência, na qual se deve estabelecer a indagação transcendental enquanto indagação da possibilidade do conhecimento transcendente" (Husserl, 1900, p. 43). A Fenomenologia nos convida a "suspender" nossos próprios valores e ir ao encontro do fenômeno - da verdade. Como diz Bicudo (2000), "Husserl afirma que perceber uma coisa é vê-la, tocá-la, cheirá-la, ouvi-la, enfim, senti-la de diferentes maneiras e de acordo com as possibilidades dos sentidos" (p. 31). Não devemos apreender o mundo como imposto à consciência, mas sim por meio de uma análise intencional, buscando-se a essência do fenômeno, abstraída de opiniões, crenças, preconceitos ou valores que possam vir a influenciá-la.

Tal idéia é reiterada por Holanda (1998), quando descreve que "para se compreender o fenômeno, é preciso renunciar a tudo o que é particular do sujeito, de modo que lhe seja permitido uma maior liberdade na compreensão da realidade deste fenômeno" (p. 6). Isso é redução fenomenológica: considerarmos nós mesmos como autores de tudo, analisar o objeto a partir da nossa própria concepção, captar a intenção, compreender a essência longe de preconceitos, e inter-relacionar o mundo com a nossa mente. Segundo Dartigues (1992), “O resultado da redução fenomenológica (...) não é só o eu penso, mas a conexão ou correlação entre o eu penso e seu objeto de pensamento" (p. 22). "A fenomenologia se tornará, conseqüentemente, o estudo da constituição do mundo na consciência" (Dartigues, p. 24).

Fenomenologia é ir às coisas mesmas, descobri-las tais quais se apresentam aos meus sentidos, tais quais eu as percebo. Mas é um 'ir em busca' aliado à minha própria experiência subjetiva concreta. É um olhar e ver, não apenas uma colocação diante de algo. É participação, envolvimento (Holanda, 1998, p. 5).

Segundo Forghieri (1993), “a reflexão fenomenológica vai em direção ao 'mundo da vida', ao mundo da vivência cotidiana imediata, no qual todos nós vivemos, temos aspirações e agimos" (p. 18). Sendo assim, a fenomenologia propõe-se a ser uma ciência descritiva das essências das vivências. "Ao invés de fatos, temos fenômenos. Fatos somente são obtidos por abstração. Fenômenos são vividos" (Holanda, 2003, p. 46). 
A fenomenologia nunca se orienta para fatos, sejam externos, sejam internos e, sim, para a realidade da consciência, para os objetos enquanto intencionados por e na consciência, isto é, para as essências ideais. Para o fenomenólogo as essências não são simples representações (o que seria colocar-se no plano psicológico) e tampouco realidades ideais hipostasiadas (o que seria colocar-se no plano metafísico). As essências ideais são para o fenomenólogo fenômenos, isto é, aquilo que se manifesta imediatamente na consciência, alcançado por uma intuição antes de toda reflexão ou juízo (Giles, 1975, p. 137).

No entanto, na publicação de 1913, Husserl apresenta a redução transcendental. Essa nova concepção da fenomenologia, na qual se tenta uma completa redução dos próprios valores, prejuízos e crenças - sendo o homem o autor de tudo -, acaba sendo considerada, por alguns, como uma tentativa idealista, por super dimensionar o papel do homem. Merleau-Ponty vem questionar esse "idealismo" (completa redução de valores e preconceitos) e introduzir as idéias da Fenomenologia existencialista, pois ninguém está livre de seus valores e crenças, e a consciência é constituída de interferências do mundo (da cultura, sociedade, crenças, conceitos...). "De acordo com Merleau-Ponty, a percepção oferece verdades como presenças, dizendo com isso tratar-se de uma verdade percebida com nitidez no momento em que o sentido se faz para o sujeito" (Bicudo, 2000, p. 31). Assim, a fenomenologia existencial se dá na relação 'homem-mundo' (consciência-objeto).

Segundo Merleau-Ponty (1999, p. 18):

O mundo fenomenológico é não o ser puro, mas o sentido que transparece na intersecção de minhas experiências, e na intersecção de minhas experiências com aquelas do outro, pela engrenagem de umas nas outras; ele é, portanto, inseparável da subjetividade e da intersubjetividade que formam sua unidade pela retomada de minhas experiências passadas em minhas experiências presentes, da experiência do outro na minha.

Com a chegada da Fenomenologia existencial, o homem é visto na realidade de sua existência (com suas crenças e valores), cuja consciência é influenciada pelo mundo que o cerca (em constante mudança), deixando de ser algo que existe por si só. Já não é a consciência do homem que constitui o mundo, mas é o homem e o mundo, numa dialética, que se constituem um ao outro. Não se pode afirmar quem age sobre quem: se o homem sobre o mundo ou vice-versa. É a esta dicotomia a qual MerleauPonty denomina de ambigüidade.

\section{Existencialismo}

Para Husserl, a consciência era pura e a redução fenomenológica totalmente possível; no entanto, para a Fenomenologia existencial, já não é possível suspender e abstrair-se de valores e preconceitos, pois, como afirmou Merleau-Ponty, a consciência é constituída de interferências constantes do mundo, numa correlação intersubjetiva em constante ambigüidade. É a existência precedendo a essência. $\mathrm{O}$ homem passa a se constituir a partir do momento em que ele existe, vive, cogita e estabelece suas crenças. Os valores que vão sendo formulados passam a fazer parte de suas escolhas e da sua relação com o mundo.

O Existencialismo surge, então, como uma corrente filosófica na qual o homem é visto como ser-no-mundo. O homem passa a ser valorizado como um indivíduo que tem sua própria subjetividade, liberdade e responsabilidade por suas escolhas. Segundo Figueiredo (1998, p. 179), "a influência da fenomenologia sobre a psicologia entendida como ciência compreensiva foi em grande parte mediada pelas doutrinas existencialistas".

Os principais pensadores existencialistas são Sören Kierkegaard, Friedrich Nietzsche, Martin Heidegger e Jean Paul Sartre. Não se pode, no entanto, deixar de citar Buber e Binswanger que também contribuíram com suas idéias e pensamentos existencialistas.

Kierkegaard (1813-1855), considerado por alguns estudiosos o pioneiro do Existencialismo, é talvez o pensador de maior destaque na corrente existencialista devido à sua influência sobre todos os filósofos fenomenólogosexistenciais (Giles, 1975, p. 5). Ele fala da busca pela existência autêntica. Para ele, "todo conhecimento deve ligarse inapelavelmente à existência, à subjetividade, nunca ao abstrato, ao racional, pois se assim proceder fracassará no intento de penetrar no sentido profundo das coisas, logo, de atingir a verdade" (Penha, 2001, p. 17). Segundo Kierkegaard, nada é uma verdade em si mesma, mas depende de como cada pessoa percebe e se relaciona com o objeto ou o fato. Há um envolvimento do sujeito com a verdade (Forghieri, 2007). E assim, a verdade está no próprio existir, no eu.

Kierkegaard insiste na necessidade da apropriação subjetiva da verdade, pois se trata de fundamentar o desenrolar do pensar em algo que seja ligado à raiz mais profunda da existência, que é o Indivíduo. (...) A própria verdade, em vez de representar uma simples equação entre ser e pensar, torna-se sinônimo de subjetividade, o que quer dizer que a verdade deve significar um compromisso pessoal do Indivíduo, já que tem raízes na existência concreta e integrada de cada Indivíduo particular (Giles, 1975, pp. 9-10).

Kierkegaard discorre sobre três estágios da existência humana: Estético (voltado para o prazer), Ético (concilia paixão e razão, reajustando-se ao social) e Espiritual (encontro com a espiritualidade para alcançar a existência humana). Kierkegaard queria encontrar uma explicação para a sua existência. Assim, através de suas idéias, tenta construir a dialética percebida nesses estágios. Para ele, 0 homem passa por esses estágios ao longo da vida, começando pelo Estético até atingir o Espiritual. 
No estágio Estético o homem está buscando um sentido para sua existência. "Convicto de que é inteiramente livre, vive ao sabor dos impulsos, procurando desfrutar, extraindo o máximo de prazer, cada instante da vida, entregando-se a todos os prazers e sensações" (Penha, 2001, p. 17). No entanto, ao permanecer nesse estágio, o homem se prende a uma existência vazia. Frustrado e não satisfeito com essa busca, o homem cai no desespero. "O desespero inconsciente de ter um eu (...). O eu é uma relação, que não se estabelece com qualquer coisa de alheio a si, mas consigo própria. Mais e melhor do que na relação propriamente dita, ele consiste no orientar-se dessa relação para a própria interioridade" (Kierkegaard, 1979, p. 195).

Para Kierkegaard (1979), ato do desespero é o ápice da angústia, mas não necessariamente uma desvantagem para o homem. Entrar na angústia é a possibilidade de cura. $\mathrm{O}$ desespero é tanto uma vantagem como uma imperfeição, em pura dialética. E assim, no desespero, o homem passa para o estágio seguinte, o da Ética. "O homem que vive no estágio estético tem o centro da realidade fora de si, ao passo que aquele que vive no estágio ético o tem em si” (Giles, 1975, p. 18).

Vivendo eticamente, sairá do marasmo existencial em que se encontrava. Mantendo ainda sua individualidade, no entanto, que não pode ignorar as exigências do mundo exterior, com suas normas e convenções. (...) No estágio ético, a personalidade do indivíduo permanece livre, mas nos limites estabelecidos pela sociedade (Penha, 2001, p. 18).

No entanto, para Kierkegaard, não é possível encontrar realização existencial plena no estágio Ético, pois é nesse estágio que surge o grande conflito entre as exigências da interioridade e da universalidade (Giles, 1975).

No estágio Ético, o Indivíduo torna-se consciente de ser responsável, mas, por outro lado, torna-se consciente do peso do universal, isto é, da necessidade de assumir a forma de existência que a coletividade lhe impõe, pois ele é submisso à lei em toda a sua generalidade (Giles, 1975, p. 20).

É somente no estágio Espiritual que o homem se depara com sua existência plena. "Deus torna-se a regra do indivíduo, a única fonte capaz de realizá-lo plenamente" (Penha, 2001, p. 19). "O homem no estágio religioso age, é sem precisar de justificativas de ordem racional" (Giles, 1975, p. 21).

Para Kierkegaard tudo é dialética. A dialética do 'eu' se desdobra desdobrando-se sem cessar ela própria, refletindo sobre si, escolhendo-se idêntica e perpetuamente se modificando. (...) O salto que leva o Indivíduo de um estágio para outro é dialético, pois esse salto é, de uma vez, o abismo e o ato que o transpõe. (...) A dialética se apresenta em Kierkegaard como oposição dos extremos, como ambigüidade, pois o 'eu' não é 'dado'; é a possibilidade do eu que é dada, e, nesse sentido, é o palco do conflito existencial (Giles, 1975, pp. 14-15)
Nietzsche (1844-1900) apresentou muitas idéias consonantes com as de Kierkegaard. Ele discorreu sobre o quanto a ciência aliena a pessoa de si mesma (Forghieri, 2007). Nietzsche fala que a vida não deveria ser um mero acidente sem significado, pois, para ele, Deus está morto, o homem é um super-homem. Isto é, cada um constrói a sua própria história através de escolhas e responsabilidades, superando o medo e a preguiça (Nietzsche, 2006). Ele propôs que se cultivasse a "vontade de poder" como objetivo maior da vida humana, o que seria a auto-realização da pessoa até o máximo de suas potencialidades, isto é, a afirmação e a realização de seus próprios direitos, concretizando suas próprias potencialidades (Forghieri, 2007). O verdadeiro poder é ser o que realmente se é. Giles (1975) relata a percepção de Nietzsche acerca da existência verdadeira:

A tarefa do homem é simplesmente fazer com que a sua existência não seja mais um simples acidente sem significado, pois o problema fundamental do homem consiste em alcançar a verdadeira existência em vez de deixar a vida se reduzir a um simples acidente. (...) Para conseguir uma existência verdadeira basta seguir a voz da consciência que diz constantemente: Torna-te aquilo que és. Faze sempre o que quiseres; mas sê desde logo daqueles que podem querer! (pp. 65-66).

Dando continuidade a esta nova maneira de perceber a existência humana, Heidegger (1889-1976) considera que antes da consciência existe o próprio homem: daisen (ser-no-mundo) (Heidegger, 2004a). Spanoudis (1981) diz que, para Heidegger, "o mundo, no qual o ser humano existe, é anterior ao mundo espacial, topográfico, interior" (p. 16). O que diferencia o humano do não-humano é a conscientização de que se é humano.

Dissemos que o ser-aí é um ente que, em cada caso, sou eu mesmo; seu ser é, em cada caso, meu. Esta definição indica um constitutivo estado ontológico, mas apenas o indica. Ao mesmo tempo, ela nos diz onticamente (ainda que de forma precária) que, em cada caso, esse ente é um 'eu' - e não os outros (Heidegger, 1981, p. 27).

Para ele, o existir como totalidade é anterior a qualquer separação entre eu e o mundo. "A compreensão do ser é em si mesma uma determinação do ser da pre-sença. (...) A pre-sença sempre se compreende a si mesma a partir de sua existência, de uma possibilidade própria de ser ou não ser ela mesma” (Heidegger, 2004a, pp. 38-39). Heidegger também reconhece a possibilidade da morte como algo que vem dar sentido à vida. Loparic (2004) cita que, para Heidegger, "enquanto ser-para-a-morte, o ser humano é um transcendente, desde sempre em movimento de ir além do mundo e de si mesmo enquanto ente mundano" (p. 49).

Cada presença deve, ela mesma e a cada vez, assumir a sua própria morte. Na medida em que "é", a morte é es- 
sencialmente e cada vez, minha. E de fato, significa uma possibilidade ontológica singular, na medida em que coloca totalmente em jogo o ser próprio de cada pre-sença. No morrer, evidencia-se que, ontologicamente, a morte se constitui pela existência e por ser, cada vez, minha. O morrer não é, de forma alguma, um dado, mas um fenômeno a ser compreendido existencialmente num sentido privilegiado, o qual deve ser delimitado mais de perto (Heidegger, 2004b, p. 20).

Assim, Heidegger contribui com o Existencialismo ao desobjetificar o ser humano, destruindo idéias do homem como um mero objeto e coisa material da natureza. De fato, todos os pensadores citados acima foram bastante importantes para a história do Existencialismo, contribuindo, cada um, com sua forma de perceber o homem no mundo. No entanto, deve-se fazer alusão também à enorme contribuição que Buber (1878-1965) proporcionou com sua filosofia do diálogo. Com sua sabedoria, Buber representou um papel muito importante no início do século XX, demonstrando atitudes de enorme compreensão à liberdade interior e uma grande fé no humano (Von Zuben, 2003).

Buber vem falar de duas atitudes que o homem pode ter diante do mundo, as quais são representadas pelas palavras-princípio EU-TU (completa integração com o mundo; vivência intensa do homem no mundo) e EUISSO (distanciamento; afastamento que o homem faz para refletir sobre o mundo, para pensar, tomar consciência de algo e falar a respeito). "O mundo como experiência diz respeito à palavra-princípio EU-ISSO. A palavra princípio EU-TU fundamenta o mundo da relação" (Buber, 2003, p. 6).

Para Buber, "o lugar dos outros é indispensável para a nossa realização” (Von Zuben, 2003, p. XVI). Pois não se pode conceber o homem sem uma relação com o mundo, uma vez que sua existência se dá no encontro com o outro. Não existe um EU puro, isolado, assim como não existe um TU sem que este seja percebido pelo EU. O homem nasce no encontro e é na relação EU-TU que cada um se constitui como um ser singular e um ser de relação. Buber releva, assim, a importância da escuta, do olhar e da disponibilidade para com o outro, o que influenciará posteriormente as psicoterapias Fenomenológico-existenciais.

Buber explica o sentido da relação EU-TU:

O homem não é uma coisa entre coisas ou formado por coisas quando, estando eu presente diante dele, que já é meu TU, endereço-lhe a palavra-princípio. Ele não é um simples ELE ou ELA limitado por outros ELES ou ELAS, um ponto inscrito na rede do universo de espaço e tempo. (...) Eu não experiencio o homem a quem digo TU. Eu entro em relação com ele no santuário da palavra-princípio. (...) Esta ação engloba uma oferta e um risco. Uma oferta: a infinita possibilidade que será imolada no altar da forma. Tudo aquilo que ainda há pouco se mantinha em perspectiva deverá ser eliminado, pois, nada disso poderá penetrar na olhar, assim exige a exclusividade própria do "face-a-face". Um risco: a palavra-princípio não pode ser proferida senão pelo ser em sua totalidade, isto é, aquele que a isso se entrega não deve ocultar nada de si, pois a obra não tolera como a árvore ou o homem, que eu descanse entrando no mundo do ISSO. É ela que domina; se eu não a servir corretamente ela se desentrutura ou ela me desestrutura. (...) O TU encontra-se comigo. Mas sou eu quem entra em relação imediata com ele (Buber, 2003, pp. 15-19).

Como é possível perceber, a palavra-princípio EU-TU representa a relação do homem com o mundo, numa abolição dos meios em busca de um encontro real. No entanto, segundo Buber (2003), no momento em que há um distanciamento, o mundo é encarado como experiência (percepção), dizendo respeito à palavra-princípio EU-ISSO. "O homem transformado em EU que pronuncia EU-ISSO coloca-se diante das coisas em vez de confrontar-se com elas no fluxo da ação recíproca” (Buber, 2003, p. 39). O TU de uma relação EU-TU (a qual é sempre vivida no presente) se contitui em ISSO após a vivência do encontro. Ao ser vista no passado, passa a ser um ISSO. Segundo Buber (2003), não se pode viver somente no presente, pois ao virar passado é que se consagra cada experiência como existência. Assim, "o homem não pode viver sem o ISSO, mas aquele que vive somente como ISSO não é homem" (Buber, 2003, p. 39).

A relação, então, encontra plenitude quando ocorre na reciprocidade e no diálogo, num constante ritmo entre as atitudes EU-TU e EU-ISSO, permitindo a aproximação e o distanciamento, o encontro e a reflexão. Contudo, vale ressaltar que a relação EU-TU não é exclusivamente inter-humana, mas que pode existir com qualquer outro ser animal, material ou espiritual. Basta haver um relacionamento de encontro com o EU, sendo o TU "homem, Deus, uma obra de arte, uma pedra, uma flor, uma peça musical” (Von Zuben, 2003, p. 40). Da mesma forma, o homem também pode ser, em alguns momentos, um ISSO na relação, permitindo um momento de isolamento e reflexão por parte do EU.

Essa forma de relacionar-se, alterando reciprocamente o EU-ISSO com o EU-TU em um ritmo constante e equilibrado, permite a construção de uma autêntica relação terapêutica, favorecendo um diálogo genuíno e um verdadeiro encontro existencial.

Ludwig Binswanger e Medard Boss, psicoterapeutas que adotaradam muitas idéias de Heidegger, também trazem grande contribuição ao Existencialismo e às Psicoterapias Fenomenológico-existenciais ao discorrerem sobre a questão da relação entre as pessoas. Eles dizem o quanto é importante, para o ser humano, poder vivenciar e compartilhar a vida com os outros, exercitando, assim, a capacidade de amar e ser amado. A existência de um homem se dá na existência de outro. Binswanger "não quer reduzir o homem a categorias biológico-naturalistas, nem a categorias tiradas das ciências do espírito, mas quer compreender o homem a partir do seu ser mais íntimo o humano - e descrever as direções fundamentais desse Ser” (Angerami-Camon, 1993, p. 90). 
Binswanger reconhece que devemos a Heidegger essa nova compreensão a respeito do homem, particularmente, à sua análise da existência humana, que tem por base a idéia de que o homem não pode mais ser compreendido em termos de alguma subjetivação, seja biológica, psicológica ou sociológica (Lessa \& Sá, 2006, p. 393).

Por fim, antes de se adentrar no movimento Humanista no tópico seguinte, é importante discorrer sobre Sartre (1905-1980), um dos pensadores mais importantes do século passado, tendo sido um destacado influente do Existencialismo e também um contribuinte para o Humanismo, considerando sua forma de compreender o homem. Para Sartre, o Existencialismo é Humanismo. "Sartre, entretanto, não aceita o humanismo estreito ou mais antigo que faz do homem, simplesmente, o valor último das preocupações humanas" (Greening, 1975, p. 21). Para ele, o homem está "constantemente se projetando para fora de si mesmo, construindo-se, realizando-se no mundo" (Nogare, 1981, p. 151). Trata-se, para Sartre, de um Humanismo existencial.

Há pelo menos um ser no qual a existência precede a essência, um ser que existe antes de poder ser definido por qualquer conceito: este ser é o homem (...). O homem, tal como o existencialista o concebe, só não é passível de uma definição porque, de início, não é nada: só posteriormente será alguma coisa e será aquilo que ele fizer de si mesmo (Sartre, 1987, p. 6).

O que Sartre quer dizer com isso é que "o homem não é nada mais do que aquilo que se projeta ser. Tal é o primeiro princípio do existencialismo (...). O homem é antes de mais nada um projeto que vive subjetivamente (...), ele será aquilo que fizer da sua vida, não havendo nada, além dele mesmo, de sua vontade, que determine seu destino" (Penha, 2001, p. 45).

Para Sartre, o homem inventa a si mesmo. Ele constrói sua história de acordo com suas escolhas e com o caminho que opta tomar. Pois "não existe determinismo, o homem é livre, o homem é liberdade” (Sartre, 1987, p. 9). Assim, Sartre fala da liberdade, da responsabilidade, da capacidade de escolha e da angústia que isso pode nos causar, e de que somos condenados a sermos livres - somos responsáveis pelos nossos próprios atos: "o homem é responsável por si mesmo (...) o homem se escolhe a si mesmo" (Sartre, 1987, p. 6).

Essa concepção existencialista do homem vai fazer com que cada um construa a sua própria definição de homem, cada um passa a ser aquilo que ele faz dele mesmo. "É a escolha que faz entre as alternativas com que se defronta que constitui sua essência” (Penha, 2001, p. 46). Cada um, a partir do seu projeto de vida, de sua formulação de crenças e valores, e de sua história construída até então, irá se constituindo pelos seus atos, suas escolhas e suas formas de viver no mundo.
Para os existencialistas, o homem é um ser livre, a sua liberdade faz dele plenamente responsável pela sua escolha e a sua escolha, sendo verdadeira, é também uma escolha que o homem faz para todos os homens. Dessa forma, $o$ ato individual acaba engajando toda a humanidade. Isto é, se ele acredita que aquilo que ele escolhe, por base em seus valores próprios, é o certo, então, ele também está escolhendo para todos os homens.

Ao afirmarmos que o homem se escolhe a si mesmo, queremos dizer que cada um de nós se escolhe, mas queremos dizer também que, escolhendo-se, ele escolhe todos os homens. (...) Escolher ser isto ou aquilo é afirmar, concomitantemente, o valor do que estamos escolhendo, pois não podemos nunca escolher o mal. O que escolhemos é sempre o bem e nada pode ser bom para nós sem o ser para todos. (...) Portanto, a nossa responsabilidade é muito maior do que poderíamos supor, pois ela engaja a humanidade inteira (Sartre, 1987, pp. 6-7).

É diante dessa liberdade de escolha, dessa responsabilidade assumida sobre os seus atos e a humanidade inteira, que a angústia aparece. "A angústia da liberdade é a angústia de optar, de fazer escolhas" (Penha, 2001, p. 57). É a angústia da decisão de uma escolha no lugar de outra. A angústia, no entanto, não nos impede de agir, mas, pelo contrário, "constitui a condição de sua ação" (Sartre, 1987, p. 8).

\section{O Humanismo}

Como foi visto, a Fenomenologia e o Existencialismo revolucionaram a Psicologia e consequentemente, como será visto mais adiante, as Psicoterapias Fenomenológicoexistenciais. O pensamento fenomenológico, o qual considera a essência do fenômeno e com o qual se tenta resgatar a verdade livre de preconceitos, proporcionou ao homem o encontro com sua consciência originária, isto é, com o seu existir. O homem entra em contato com a experiência viva e pré-reflexiva. Assim, nessa luta fenomenológica pela essência, ele descobre o seu eu, descobre a si mesmo na relação com o mundo e com a sua própria percepção de si e do mundo. Com isso, depara-se com a percepção do valor humano - da existência humana acima de tudo. Surge o pensamento humanista. O homem passa a ser capaz de olhar para si e refletir sobre a sua existência. Cada vivência passa a ter um sentido e um significado único, e passa a influenciar de uma forma diferente.

Como afirma Forghieri (2007):

Desenvolvemo-nos mediante nossas vivências com a natureza e com outras pessoas, vivências que podem ser imediatas ou racionais, agradáveis ou desagradáveis, com as quais podemos nos sintonizar, atribuindo-lhes significados, assim como podemos delas nos esquivar, distorcendo-as ou negando-lhes significados. (...) Nós nos tornamos quem somos a partir de nossas vivências no mundo, e estas, por 
sua vez, são influenciadas pelo indivíduo que vamos nos tornando (pp. 93-94).

Sendo assim, o homem se reconhece como um ser em construção, em constante mudança, crescimento e atualização. A Fenomenologia e, principalmente, o Existencialismo foram despertando nos seres humanos seus valores e suas singularidades, fazendo brotar as primeiras sementes que futuramente vão dar origem ao movimento Humanista. O Humanismo, de fato, surgiu com o apogeu do Cristianismo e os novos olhares que o Renascimento foi dando ao homem na arte, na religião e na literatura. Segundo Bühler (1975), é no Renascimento que se dá o apogeu do Humanismo com o desenvolvimento da liberdade de pensamento.

$\mathrm{O}$ movimento Humanista veio resgatar valores humanos esquecidos e re-construir um novo foco ao homem enquanto ser concreto, singular, repleto de valores e potencialidades. Entre os pensadores humanistas mais importantes, destacam-se os psicólogos americanos Carl Rogers (1902-1987) e Abraham Maslow (1908-1970), os quais contribuíram enormemente com suas teorias, principalmente com suas crenças na potencialidade do homem e na tendência humana de crescer e atualizar-se.

Segundo Lima (2005), as duas doutrinas, tanto a Humanista como a Existencialista, levam pontos em comum no que se refere à visão de homem. Ambas reconhecem o homem como fonte e centro de valores, concordando que o homem está constantemente em movimento, na busca de superar a si mesmo. No entanto, possuem divergências. "Enquanto os existencialistas afirmam que cabe ao homem criar suas possibilidades, os humanistas falam que seu papel é de descobrir as potencialidades que lhes são inerentes" (Erthal, 1999, p. 47).

Os existencialistas são vistos como sendo mais negativos pelo fato de acreditarem que sempre existe a possibilidade do homem fazer escolhas destrutivas para si mesmo. Enquanto os humanistas, de forma mais otimista, acreditam que os homens, encontrando-se em condições favoráveis, têm a tendência a fazer as melhores escolhas para si e para os outros. Os humanistas acreditam em um potencial humano que o impulsiona ao crescimento e à atualização (Lima, 2005).

Para Rogers, os indivíduos possuem dentro de si os recursos para a auto-compreensão, modificação de seus auto-conceitos, de suas atitudes e de seus comportamentos. Cada ser humano possui a tendência ao crescimento, amadurecimento e atualização (Rogers, 1994). O conceito de tendência atualizante de Rogers é uma das expressões mais importantes na Psicologia Humanista.

A tendência à atualização está relacionada àquilo "que o sujeito percebe como valorizador ou enriquecedor" (Rogers, 1975, p. 41). Para Rogers e Rosenberg (1977), o homem é seu próprio arquiteto. Sendo assim, a tendência atualizante consiste em delimitar uma confiança na capacidade e potencialidade de cada um.
No entanto, Rogers (1994) destaca que, apesar dos indivíduos possuírem dentro deles os recursos para a auto-compreensão, modificação de seus auto-conceitos, de suas atitudes e de seus comportamentos, e tendência ao crescimento, esses recursos somente serão ativados se houver um clima facilitador.

De forma semelhante, Maslow acredita que os homens estão sempre em busca de suprir suas necessidades, indo, assim, em direção a uma auto-realização. Para ele, os homens estão sempre em busca de preencher suas necessidades (Lima, 2005). A maioria dos homens quer "suprir o que pensam faltar-lhes do mundo externo. (...) Mas também existe em todos os homens uma sensação de que possuem algo em seu íntimo que procura expressar-se, algo que se concretiza quando encontra sua articulação apropriada” (Iyer, 1975, pp. 248-249). Isso seria justamente o potencial para a auto-realização ou tendência atualizante.

Lima (2005) explica que "esta tendência para o crescimento impele o homem na busca do crescimento, caracterizado por Maslow como a capacidade de aceitação de si e dos outros, a espontaneidade e a capacidade de transcender a si mesmo para ir ao encontro do outro nas relações interpessoais e na sociedade” (p. 49). Para Rogers, as pessoas possuem nelas mesmas a capacidade para o crescimento, mudança e desenvolvimento pessoal. "O ser humano tem a capacidade, latente ou manifesta, de compreenderse a si mesmo e de resolver seus problemas de modo suficiente para alcançar satisfação e eficácia necessárias ao funcionamento adequado” (Rogers, 1994, p. 39).

O Humanismo trouxe para a Psicologia uma importante contribuição com sua "atitude concreta em favor do homem” (Amatuzzi, 2001, p. 17). Tal movimento influenciou para um despertar de valores que levaram a uma maior e mais completa compreensão do homem, no qual se consideram suas potencialidades, responsabilidade, liberdade de escolha e a tendência para o crescimento e atualização. "O principal valor humanista é, portanto, o enfoque na relação: a existência humana se realiza em um contexto interpessoal” (Erthal, 1999, p. 43). Isto é, no momento em que se valoriza o homem, também se está valorizando a relação entre eles, valorizando o compartilhamento e as inter-relações pessoais. Essa nova perspectiva trouxe, particularmente para a relação terapêutica nas Psicoterapias Fenomenológico-existenciais, os valores de respeito e igualdade que impulsionaram a um verdadeiro encontro terapeuta-cliente.

Falar de humanismo em psicoterapia, portanto, é falar de uma questão de postura, de atitude. Significa colocar-se na experiência vivida no momento presente, pois é somente na vivência atual, em interação com o outro, que pode realmente se dar o conhecimento e atingir o significado da experiência. Na prática clínica, significa que é na relação entre terapeuta e cliente que se dá o desvelamento da pessoa e se pode chegar ao sentido que o cliente dá às questões trazidas (Lima, 2005, p. 51). 


\section{As Psicoterapias Fenomenológico-Existenciais}

Como se pode ver, a Psicologia, influenciada pelos pensamentos da Fenomenologia, do Existencialismo e do Humanismo foi modificando gradualmente, e de forma bastante significativa, a sua maneira de perceber e lidar com o homem. Muitos psicoterapeutas foram tocados pelos conceitos do movimento Fenomenológicoexistencial e pelos valores advindos do Humanismo, o que influenciou as novas formas de relacionamento terapeuta-cliente, dando origem, assim, às Psicoterapias Fenomenológico-existenciais, também conhecidas como Psicoterapias Humanista-existenciais ou Existencialhumanistas.

Dentre as principais e mais conhecidas abordagens terapêuticas dentro dessa perspectiva fenomenológico-existencial encontram-se a Abordagem Centrada na Pessoa (ACP), a Gestalt-terapia e a Logoterapia. Apesar dessas psicoterapias não possuírem um corpo teórico único, apresentando divergências de acordo com sua escola de pensamento (umas mais existenciais, outras mais humanistas), todas têm em comum o respeito pela pessoa humana (Matson, 1975). Possuem uma perspectiva de homem como um ser consciente, autônomo, afetivo e repleto de emoções próprias, sentimentos, sonhos, anseios, crises e desejos. Dessa forma, na relação terapêutica, o cliente é sempre percebido como "uma pessoa com capacidade para expandir sua consciência e decidir, por si mesmo, a futura orientação a ser dada à sua vida” (Corey, 1986, p. 223).

É possível perceber, em todas elas, a forte contribuição de Heidegger com seu conceito sobre a noção do homem como ser processual, que compreende a si mesmo enquanto ser-no-mundo e ser-com, no ato singular e concreto de sua existência compartilhada com os outros (Lima, 2005). Da mesma forma se percebe os pensamentos de Sartre, os quais acreditam na liberdade e na responsabilidade humana e Nietzsche, que defende o homem como autor de sua própria história.

Os terapeutas fenomenológico-existenciais, de uma maneira geral, apresentam uma postura visando um verdadeiro encontro com o cliente, baseando-se nos elementos do inter-humano de Buber (2003) de respeitar e valorizar a criatividade existencial emergente em cada um. Assim, não se trata de dar orientações nem de trazer interpretações prontas aos clientes, como às vezes acontece em psicoterapias de outras abordagens. Pelo contrario, trata-se de permitir que cada um, com suas próprias potencialidades e capacidade para o crescimento, como já defendiam os humanistas Maslow e Rogers, busque encontrar o seu próprio caminho a partir de suas próprias observações e reflexões. Pois "uma psicologia fenomenológica procura revelar o ser humano para si próprio, fazendo-o observarse aos demais, refletir sobre si próprio e sobre suas observações" (Holanda, 1998, p. 13).
Os psicoterapeutas de orientação científico-naturalista procuravam, muitas vezes, encaixar as pessoas na teoria, ao invés de voltar-se para uma descrição fenomenológica da existência singular. Essas tentativas de enquadrar os pacientes nos modelos teóricos eram pródigas em explicações do sofrimento, mas quase sempre estéreis no sentido de propiciar relações terapêuticas que promovessem transformações existenciais efetivas. A Psicoterapia Existencial funda-se no “cuidado", enquanto “ser-no-mundo-com-o-outro", e não em interpretações apriorísticas ou explicações casuais sobre a realidade vivencial do paciente. (...) O psicoterapeuta remete o indivíduo a si, estimulando-o a reconhecer sua impessoalidade e a questionar-se no sentido de encontrar suas próprias respostas para as questões que a vida lhe apresenta (Lessa \& Sá, 2006, p. 394).

Com isso, a preocupação do terapeuta fenomenológico-existencial, além de tentar compreender melhor a pessoa do cliente, é também a de levá-lo a uma autocompreensão que o permita ressignificar seu futuro, podendo assim aceitar a responsabilidade que acompanha a liberdade de conduzir sua própria vida (Corey, 1986). O que se quer é ajudar a pessoa a encontrar um sentido para a sua vida.

Na relação terapêutica, procura-se desenvolver uma atitude dialógica e uma postura de aceitação para com o cliente, como apresentadas na filosofia de Buber sobre inter-relação humana, defendendo a fala como meio de expressão e encontro autêntico (EU-TU). Consoante com as teorias de Heidegger, o EU-TU de Buber permitiriam o encontro existencial em que se revelariam terapeuta e cliente. "A perspectiva existencial valoriza o encontro no aqui-agora, onde o outro comparece com sua alteridade própria, afetando e sendo afetado, e não apenas enquanto uma representação" (Lessa \& Sá, 2006, p. 395).

Ao construir essa relação autêntica com o cliente, aceitando-o e disponibilizando-se para ouvir e acolher seus sentimentos e suas atitudes, o terapeuta está proporcionando a ele um ambiente facilitador para explorar, vivenciar, entrar em contato e acolher seus próprios sentimentos e atitudes. Ao se perceber com mais clareza e aceitar-se mais, o cliente terá mais capacidade para tomar suas próprias decisões e assim descobrir uma nova maneira de ser (Corey, 1986).

Tal relação acontece quando o terapeuta, de forma autêntica, possui e sabe demonstrar empatia pelo cliente, apresentando-se concernente com os valores humanistas, isto é, mostrando-se um profissional que verdadeiramente se entrega na relação, aceitando o outro como ele é. "O terapeuta, neste sentido é muito mais 'pessoa' (como assinala Rogers) do que propriamente um papel a ser desempenhado" (Holanda, 1998, p. 15).

A empatia seria a compreensão e a aceitação que o terapeuta tem com o cliente e seus sentimentos, isto é, a arte de se colocar no lugar do outro. O terapeuta "sente precisamente os sentimentos e os significados pessoais que estão sendo vivenciados pela cliente e lhe comunica 
esta compreensão” (Rogers, 1978, p. 19). O cliente existe na relação empática. Percebe-se aqui um paralelo entre o conceito de Rogers e as idéias de Buber. "O homem se torna EU na relação com o TU” (Buber, 2003, p. 32). "Buber também referiu-se à necessidade de termos nossa existência confirmada por outra pessoa. A empatia proporciona esta confirmação necessária de que existimos como pessoa individual, valorizada e possuidora de uma identidade” (Rogers, 1977, pp. 82-83).

Dessa forma, através do sentimento empático que o terapeuta tem pelo cliente, o profissional privilegia o ser do cliente, o que ele sente e o que ele pensa, isto é, o seu existir naquele momento. Com isso, ele faz com que o cliente possa reconhecer-se a si mesmo, aceitar-se a si mesmo e afirmar sua realidade, sendo assim fonte de criatividade, de mudança e força motriz do processo de psicoterapia e da sua própria vida.

\begin{abstract}
Quando uma pessoa é compreendida de maneira perceptiva, ela entra em contato mais próximo com uma variedade maior de suas vivências. Este fato lhe proporciona um referencial mais amplo ao qual recorrer para compreender a si mesma e nortear seu comportamento. Quando a empatia é adequada e profunda também pode desbloquear um fluxo de vivências e permitir que ele siga seu curso natural (Rogers, 1977, p. 83).
\end{abstract}

Tais conceitos de empatia, aceitação e autenticidade citados nos parágrafos anteriores foram descritos por Rogers como sendo atitudes chaves para uma boa relação terapêutica. Carl Rogers, uma das personalidades mais marcantes do movimento Humanista no século XX, foi o criador da Abordagem Centrada na Pessoa (ACP). Sendo assim, são termos utilizados especialmente na fundamentação teórica da ACP. Outras abordagens Fenomenológicoexistenciais, por possuírem escolas teóricas distintas e utilizarem outros termos, podem apresentar diferenças na forma de conceituar e explicar o processo da relação terapêutica. Pois, como já foi comentado anteriormente, cada abordagem apresenta suas técnicas e particularidades. No entanto, os fundamentos teóricos e filosóficos básicos, ou seja, a visão Humanista e a perspectiva FenomenológicoExistencial estão presentes tanto na Abordagem Centrada na Pessoa, como na Gestalt-terapia e na Logoterapia.

\section{Conclusão}

Com o objetivo de conhecer melhor as Psicoterapias Fenomenológico-Existenciais, foi feito, neste artigo, um breve percorrido pelos principais fundamentos da Fenomenologia, do Existencialismo e do Movimento Humanista, observando as suas diversas contribuições para a origem dessas psicoterapias.

Como foi visto, a Fenomenologia revolucionou a Psicologia ao introduzir uma nova forma de perceber o homem como um ser em constante relação com o mundo, com sua cultura, sua história e com os outros ao seu redor. Surgiu, assim, a Fenomenologia existencial de Husserl, para a qual homem e mundo estão sempre constituindo um ao outro, em constante dialética. Tal perspectiva deu origem ao Existencialismo, onde o homem é valorizado por sua própria subjetividade, liberdade e responsabilidade de escolhas. Isto é, o homem passa a ser considerado um ser livre e capaz de construir a sua própria história, inventando-se a si mesmo em cada escolha e em cada ato. Assim, o movimento Humanista, fortalecido pelos fundamentos trazidos do Existencialismo, veio trazer ainda mais foco ao homem e destacar os valores humanos, defendendo a potencialidade de cada um e a tendência humana de crescer e atualizar-se.

Essa forma de perceber e valorizar o homem, acreditando em sua potencialidade e em sua capacidade de construir seu próprio caminho, sendo o homem um ser em constante relação com os outros e com o mundo ao seu redor, torna-se um dos principais fundamentos das Psicoterapias Fenomenológico-Existenciais. Como foi visto nesse estudo, a relação terapêutica construída com profissionais que abordam essa perspectiva baseia-se em um verdadeiro encontro existencial (EU-TU), valorizando o aqui-agora e respeitando a alteridade de cada cliente. O objetivo é levar a pessoa a encontrar um sentido em sua vida, sabendo que cada um é capaz de fazer as melhores escolhas para si. O papel do terapeuta seria de ajudar o cliente a ter uma melhor auto-compreensão e aceitação de si mesmo, o que o permitirá ressignificar sua vida.

Assim, as Psicoterapias Fenomenológico-Existenciais constituem suas teorias e formas de atuação embasadas nos princípios da empatia, autenticidade, respeito e crença na potencialidade humana. Princípios estes que tiveram origem nos fundamentos da Fenomenologia, do Existencialismo e do movimento Humanista, os quais percorreram toda a história da Psicologia até os dias atuais.

\section{Referências Bibliográficas}

Amatuzzi, M. M. (2001). Por uma psicologia humana. Campinas, SP: Editora Alínea.

Angerami-Camon, V. A. (1993). Psicoterapia existencial. São Paulo: Pioneira.

Bicudo, M. A. V. (2000). Fenomenologia: confrontos e avanços. São Paulo: Cortez.

Buber, M. (2003). Eu e tu. (6 Ed., N. A. Von Zuben, Trad.). São Paulo: Centauro.

Bühler, C. (1975). Psicologia existencial e humanista: respostas a desafios contemporâneos. In: T. C. Greening (Org.). Psicologia existencial-humanista (pp. 31-65). Rio de Janeiro: Zahar.

Corey, G. (1986). Técnicas de aconselhamento e psicoterapia. Rio de Janeiro: Campus. 
Dartigues, A. (1992). Um positivismo superior. In: A. Dartigues. $O$ que é fenomenologia? (pp.7-28). São Paulo: Moraes.

Enciclopédia Mirador Internacional (1982). Fenomenologia. São Paulo/Rio de Janeiro: Encyclopaedia Britannica do Brasil Publicações Ltda. (vol. 09, pp. 4543-4546).

Erthal, T. C. (1999). Terapia vivencial: uma abordagem existencial em psicoterapia. Petrópolis: Vozes.

Figueiredo, L. C. (1991). Matrizes do pensamento psicológico. Petrópolis: Vozes.

Figueiredo, L. C. (2002). Matrizes do pensamento psicológico. Petrópolis: Vozes.

Forghieri, Y. C. (2007). Aconselhamento terapêutico: origens, fundamentos e prática. São Paulo: Thomson Learning.

Forghieri, Y. C. (1993). Psicologia fenomenológica - fundamentos, método e pesquisas. São Paulo: Pioneira.

Giles, T. R. (1975). História do existencialismo e da fenomenologia. Volume I. São Paulo: E.P.U.

Greening, T. C. (1975). Introdução. In: T. C. Greening (Org.) Psicologia existencial-humanista (pp. 13-28). Rio de Janeiro: Zahar.

Heidegger, M. (1981). Todos nós... ninguém: um enfoque fenomenológico do social. São Paulo: Moraes

Heidegger, M. (2004a). Ser e tempo. Parte I. (13ª. Ed., M. S. S. Schuback, Trad.). Petrópolis: Vozes; Bragança Paulista: Universidade São Francisco.

Heidegger, M. (2004b). Ser e tempo. Parte II. (11ª . Ed., M. S. S. Schuback, Trad.). Petrópolis: Vozes; Bragança Paulista: Universidade São Francisco.

Holanda, A. F. (1998). Fenomenologia, Psicoterapia e Psicologia Humanista. Estudos de Psicologia. Campinas: 14(2): 33-46.

Holanda, A. F. (2003). Pesquisa fenomenológica e psicologia eidética: elementos para um entendimento metodológico. In: Maria Alves de Toledo Bruns e Adriano Furtado Holanda (Orgs.). Psicologia e fenomenologia: reflexões e perspectivas (pp. 41-64). Campinas: Alínea Editora.

Husserl, E. (1900). Conferências de Paris. Lisboa: Edições 70.

Iyer, R. N. (1975). O homem auto-realizador na sociedade. In: T. C. Greening (Org.). Psicologia existencial-humanista (pp. 239-257). Rio de Janeiro: Zahar.

Kierkegaard, S. A. (1979). Diário de um sedutor; Temor e tremor; O desespero humano. São Paulo: Abril Cultural.

Lessa, J. M. \& Sá, R. N. (2006). A relação psicoterapêutica na abordagem fenomenológico-existencial. Análise Psicológica, 3(24): 393-397.

Lima, M. C. F. (2005). Intersubjetividade e psicoterapia: compreendendo a relação terapêutica no acompanhamento psicológico. Monografia do curso de Especialização, Universidade Federal do Rio Grande do Norte, Natal.

Loparic, Z. (2004). Heidegger. Rio de Janeiro: Jorge Zahar Editor.
Matson, F. W. (1975). Teoria humanista: a terceira revolução em psicologia. In: T. C. Greening (Org.). Psicologia existencialhumanista (pp. 69-81). Rio de Janeiro: Zahar.

Merleau-Ponty, M. (1999). Fenomenologia da percepção. $2^{\mathrm{a}}$ edição. São Paulo: Martins Fontes.

Nietzsche, F. (2006). Humano, demasiado humano. São Paulo: Escala.

Nogare, P. D. (1981). Humanismos e anti-humanismos: introdução à antropologia filosófica. Petrópolis: Vozes.

Penha, J. (2001). O que é existencialismo. Coleção Primeiros Passos. São Paulo: Brasiliense.

Raffaelli, R. (2004). Husserl e a psicologia. Estudos de Psicologia, 9(2), 211-215.

Rogers, C. R. (1977). Uma maneira negligenciada de ser: a maneira empática. In: C. R. Rogers \& R. L. Rosenberg. A Pessoa como centro (pp.69-89). São Paulo, EPU.

Rogers, C. R. (1978). Sobre o poder pessoal. São Paulo: Martins Fontes.

Rogers, C. R. (1994). As Condições necessárias e suficientes para a mudança terapêutica de personalidade. In: J. K. Wood (org). Abordagem centrada na pessoa (pp. 155-177). Vitória, ES: Editora Fundação Ceciliano Abel de Almeida.

Roehe, M. V. (2006). Uma abordagem fenomenológico-existencial para a questão do conhecimento em psicologia. Estudos de Psicologia, 11(2), 153-158.

Sartre, J. (1987). O existencialismo é um humanismo; a imaginação; questão de método. $3^{\mathrm{a}}$ edição. São Paulo: Nova Cultural.

Spanoudis, S. (1981). Apresentação - A todos que procuram o próprio caminho. In: M. Heidegger. Todos nós... ninguém: um enfoque fenomenológico do social (pp. 9-22). São Paulo: Moraes.

Von Zuben, N. A. (2003). Introdução. In: M. Buber. Eu e tu. (6 $6^{\text {a }}$ ed., N. A. Von Zuben, Trad., pp. 5-78). São Paulo: Centauro.

Zilles, U. (1996). Introdução. In: E. Husserl. A crise da humanidade européia e a filosofia. Porto Alegre: EDIPUCRS.

Beatriz Furtado Lima - Psicóloga, Especialista em Psicologia Clínica pela Universidade Federal do Rio Grande do Norte (UFRN) e Mestranda da Universidade de Cádiz (Espanha). Email: <beatrizflima@gmail.com>

Recebido em 26.03.08 Primeira Decisão Editorial em 26.06.08 Aceito em 12.08.08 